[AMERican Journal of Science, Vol. 314, November, 2014, P. 1300-1318, DOI 10.2475/09.2014.03]

\title{
SODIUM-POTASSIUM INTERDIFFUSION IN POTASSIUM-RICH ALKALI FELDSPAR II: COMPOSITION- AND TEMPERATURE-DEPENDENCE OBTAINED FROM CATION EXCHANGE EXPERIMENTS
}

\author{
ANNE-KATHRIN SCHÄFFER ${ }^{\dagger} *$, ELENA PETRISHCHEVA*, GERLINDE HABLER*, \\ RAINER ABART*, DIETER RHEDE**, and GERALD GIESTER*
}

ABSTRACT. Na-K interdiffusion in disordered potassium-rich alkali feld
studied experimentally using cation exchange between gem quality sanidine
Eifel and alkali-halide melt at temperatures of $800{ }^{\circ}$ to $1000{ }^{\circ} \mathrm{C}$ and at
ambient pressure. Sodium-potassium interdiffusion coefficient $D_{\mathrm{NaK}}$ was det
for potassium mole fractions in the range $0.65 \leq X_{\mathrm{Or}} \leq 0.99$. At $0.65 \leq X_{\mathrm{Or}} \leq$
sodium-potassium interdiffusion coefficient is largely independent of composition
$X_{\text {Or }} \geq 0.95$, it rises sharply with increasing potassium mole fraction. Dif
perpendicular to $(001)$ is about one order of magnitude faster and less
temperature dependent than perpendicular to $(010)$. The parameters of the A
equation describing the temperature dependence of the sodium-potassium in
sion coefficient $D_{\mathrm{NaK}}=D_{0} \mathrm{Exp}\left(-E_{A} / R T\right)$ were estimated as
\[ D_{0}^{\perp(001)}(0.92)=5.18 \cdot 10^{-8} \mathrm{~m}^{2} / \mathrm{s}, \quad \mathbf{E}_{\mathrm{A}}^{\perp(001)}(0.92)=179 \mathrm{~kJ} / \mathrm{mole} \]
\[ D_{0}^{\perp(001)}(0.98)=1.82 \cdot 10^{-7} \mathrm{~m}^{2} / \mathrm{s}, \quad \mathbf{E}_{\mathrm{A}}^{\perp(001)}(0.98)=182 \mathrm{~kJ} / \mathrm{mole} \]
$D_{0}^{\perp(010)}(0.92)=5.81 \cdot 10^{-5} \mathrm{~m}^{2} / \mathrm{s}, \quad \mathbf{E}_{\mathrm{A}}^{\perp(010)}(0.92)=272 \mathrm{~kJ} / \mathrm{mole}$
$D_{0}^{\perp(010)}(0.98)=1.34 \cdot 10^{-4} \mathrm{~m}^{2} / \mathrm{s}, \quad \mathbf{E}_{\mathrm{A}}^{\perp(010)}(0.98)=269 \mathrm{~kJ} / \mathrm{mole}$

The results of our direct determinations are compared with theoretical calculations using the corresponding sodium- and potassium tracer-diffusion coefficients, and the processes underlying the observed composition- and temperature dependence of sodium-potassium interdiffusion are discussed. dence

Key words: Alkali feldspar, Na-K interdiffusion, composition- temperature depen-

\section{INTRODUCTION}

Alkali feldspar forms a solid-solution between the sodium $\left(\mathrm{NaAlSi}_{3} \mathrm{O}_{8}\right)$ and potassium $\left(\mathrm{KAlSi}_{3} \mathrm{O}_{8}\right)$ end-member components. The alkali feldspars are among the most abundant rock-forming minerals in the Earth's crust and are involved in a multitude of mineral reactions (Spear, 1993). Their occurrence in virtually every crustal environment makes it vital to have a sound knowledge of their properties, the large variety of intracrystalline microstructures they exhibit, and the processes underlying their formation. In particular, the chemical compositions, zoning patterns, as well as size and composition of exsolution lamellae may bear important petrogenetic information (Yund, 1983; Abart and others, 2009; Petrishcheva and Abart, 2009; Benisek and others, 2010). It is highly relevant for extracting quantitative information from such phenomena that the kinetics of diffusion, in particular the kinetics of sodium-potassium interdiffusion in alkali feldspar, are known. Reviews of the state of knowledge on diffusion in alkali feldspar may be found in Freer (1981), Brady (1995) and Cherniak (2010).

\footnotetext{
* University of Vienna, Department of Lithospheric Research, Althanstrasse 14, A-1090 Vienna dam

** Helmholtzzentrum Potsdam, Deutsches GeoForschungsZentrum, Telegraphenberg, D-14473 Pots-

+ Corresponding author: anne-kathrin.schaeffer@univie.ac.at
} 
Major efforts to understand diffusion of $\mathrm{Na}^{+}$and $\mathrm{K}^{+}$in alkali feldspars have been made in the 1970 s and 80 s. Most of these early studies focused on the quantification of Na- and K- tracer-diffusion using isotope tracer experiments. Both, the sectioning method (Sippel, 1963; Bailey, 1971, Giletti and Shanahan 1997), as well as bulk exchange experiments (Bailey, 1971; Lin and Yund, 1972; Foland, 1974; Giletti and others, 1974; Kasper, ms, 1975) were employed. The determination of the Na- and Ktracer-diffusion coefficients was motivated in part by the notion that sodium-potassium interdiffusion coefficient $D_{\mathrm{NaK}}$ can be calculated from the respective tracer-diffusion coefficients (Manning, 1968). However, the results of the early studies on $\mathrm{Na}$ - and Ktracer-diffusion in alkali feldspar show considerable scatter, probably due to the insufficient homogeneity of the starting material used and the limited analytical possibilities available at the time. Calculation of $D_{\mathrm{NaK}}$ from the tracer-diffusion coefficients is therefore problematic, rendering direct determination of $D_{\mathrm{NaK}}$ by interdiffusion experiments necessary.

Relatively few studies dealing with the direct determination of the sodiumpotassium interdiffusion coefficient have been conducted. Based on the notion that alkali feldspar can exchange $\mathrm{Na}^{+}$and $\mathrm{K}^{+}$with its surroundings without changing the state of Si-Al ordering on the tetrahedral site, Petrovic (1972) performed cation exchange experiments between alkali feldspar and an alkali-chloride salt melt. Under dry conditions, cation exchange can only occur by the interdiffusion of $\mathrm{Na}^{+}$and $\mathrm{K}^{+}$on the alkali sub-lattice of the feldspar. The chemical alteration of alkali feldspar produced by cation exchange can thus be used for direct determination of the sodiumpotassim interdiffusion coefficient from concentration-distance data. One of the main problems with direct determinations of the sodium-potasium interdiffusion coefficient in alkali feldspar is related to the formation of micro-cracks. The lattice parameters of alkali feldspar show considerable compositional dependence (Kroll and others, 1986; Angel and others, 2012), and any composition heterogeneity introduced into an alkali feldspar crystal during cation exchange induces coherency stress. This may lead to fracturing, if the change in chemical composition exceeds about 10 mole percent for chemical shifts towards more sodium-rich compositions, and about 15 mole percent for chemical shifts towards more potassium-rich compositions (Petrović, 1972, 1973; Neusser and others, 2012; Scheidl and others, 2014). Special care must be taken during direct determination of the sodium-potassium interdiffusion coefficient in alkali feldspar to avoid fracturing.

Keeping the chemical shifts lower than 14 mole percent Petrovic (1972) derived $D_{\mathrm{NaK}}$ from a chemical shift of albite to a composition of $X_{\mathrm{Or}}=0.1$, and from a chemical shift of adularia with initial $X_{\mathrm{Or}}=0.86$ to $X_{\mathrm{Or}}=1.00$, where $X_{\mathrm{Or}}$ is the potassium mole fraction in the alkali sublattice of the alkali feldspar. Whereas for the composition interval $0 \leq X_{\mathrm{Or}} \leq 0.1$ the sodium-potassium interdiffusion coefficient was found to be independent of composition, a substantial compositional dependence was found for the composition interval $0.86 \leq X_{\mathrm{Or}} \leq 1.00$. Irrespective of the composition domain the activation energy was determined at about $250 \mathrm{~kJ} / \mathrm{mole}$.

An alternative approach pursued by Christoffersen and others (1983) was to use diffusion couple experiments for direct determination of $D_{\mathrm{NaK}}$. Single crystals of albite and adularia were put into contact at a polished face and annealed at $900{ }^{\circ} \mathrm{C}$ and 1000 ${ }^{\circ} \mathrm{C}$ and at pressures of 0.5 and $1.5 \mathrm{GPa}$. During annealing the initial composition jump across the contact plane evolved into a sigmoidal concentration profile by sodiumpotassium interdiffusion. From a pronounced asymmetry of the concentration profile across the contact plane a compositional dependence of $D_{\mathrm{NaK}}$ was inferred, and the Boltzmann-Matano method (Matano, 1933) was used for extracting $D_{\mathrm{NaK}}(c)$. A clear compositional dependence of $D_{\mathrm{NaK}}$ with a minimum at $X_{\mathrm{Or}} \approx 0.4$ and a strong increase towards more potassium-rich compositions was found. Diffusion in the direction 
perpendicular to (010) was found to be about one order of magnitude slower than in the direction perpendicular to (001), indicating diffusion anisotropy. Reasonable qualitative agreement between $\mathrm{Na}$ - and $\mathrm{K}$ - tracer diffusion coefficients calculated from self-diffusion coefficients by Kasper (ms, 1975) and Foland (1974), and the direct determination was found. The absolute values of the direct determinations were, however, substantially lower than those predicted theoretically. Due to the limitations of the method, the analysis of Christoffersen and others (1983) was restricted to the composition range of $0.10 \leq X_{\mathrm{Or}} \leq 0.80$, and the composition range $0.80 \leq X_{\mathrm{Or}} \leq 1.00$ was not covered. Many alkali feldspars, however, fall into this composition range, and knowledge of the diffusion properties of potassium-rich alkali feldspars is of great interest. Furthermore, a pronounced compositional dependence of $D_{\mathrm{NaK}}(c)$ was documented in this composition range (Neusser and others, 2012; Petrishcheva and others, 2014). It must be noted at this point that the composition shifts within the two crystals of the diffusion couple were about 50 mole percent close to the contact plane, and mechanical effects related to the associated change in the lattice parameters of the two crystals may be expected. Such effects have, however, not been documented in the study of Christoffersen and others (1983), and the potential effects on sodiumpotassium interdiffusion in these experiments are not known.

The sodium-potassium interdiffusion coefficient was also determined from homogenization experiments done on perthitic alkali feldspar (Brady and Yund, 1983; Hokason and Yund, 1986). These determinations are, however, restricted to the direction perpendicular to the exsolution lamellae and usually cover a rather limited composition range. Brady and Yund (1983) used a synthetic perthite prepared from natural adularia, and natural perthite as starting materials. The samples were annealed at $600{ }^{\circ} \mathrm{C}$ in $\mathrm{Pt}$ containers open to the atmosphere. They were removed repeatedly to take precession photographs in order to document the progression of homogenization. The average interdiffusion coefficient was then calculated using the diffusion equation for the finite, one-dimensional geometry of a lamellar intergrowth by Crank (1975), the critical values being the time needed for homogenization and the lamellar spacing. They point out that the sodium-potassium interdiffusion coefficient cannot be constant for the conditions. Hokason and Yund (1986) conducted the same experiments using a number of natural feldspars, focusing on the influence of the degree of ordering on the homogenization. It was found that disordered crystals homogenized at $600{ }^{\circ} \mathrm{C}$, in contrast, ordered feldspars did not homogenize even when tempered at $1000{ }^{\circ} \mathrm{C}$.

More recently cation exchange experiments similar to those of Petrović (1972) were done using gem quality sanidine from the Eifel with an initial composition of $X_{\text {Or }}=0.84$ and $\mathrm{KCl}$ melt, which are represented in the companion paper by Petrishcheva and others (2014). Single crystals of sanidine were machined to plates $3 \times 3 \times 1 \mathrm{~mm}$ with polished bottom and top faces. Six types of differently oriented plates were used for the cation exchange experiments. From the chemical profiles obtained in six different crystallographic directions the full diffusivity tensor and its compositional dependence in the composition range $0.86 \leq X_{\mathrm{Or}} \leq 0.99$ were determined for $850{ }^{\circ} \mathrm{C}$ and 1 bar. Sodium-potassium interdiffusion was found to be markedly anisotropic with slow diffusion in the direction perpendicular to (010). A substantial diffusion anisotropy was also found within the (010) plane with relatively fast diffusion in the direction perpendicular approximately to (101) and relatively slow diffusion in the direction perpendicular approximately to $(10 \overline{1})$. In the composition range $0.86 \leq$ $X_{\mathrm{Or}} \leq 0.95$ only a weak compositional dependence of $D_{\mathrm{NaK}}$ was found, whereas at $X_{\mathrm{Or}} \geq 0.95$ a substantial increase of $D_{\mathrm{NaK}}$ with increasing $X_{\mathrm{Or}}$ was detected.

In this study we present direct determinations of the Na-K interdiffusion coefficients in the range of $800{ }^{\circ} \mathrm{C}$ to $1000{ }^{\circ} \mathrm{C}$ and covering the composition range $0.65 \leq$ 
TABLE 1

Electron microprobe analyses of both starting materials

\begin{tabular}{|c|c|c|c|c|c|c|c|}
\hline $\mathrm{wt} \%$ & V5 & V14 & V16 & V22 & ERN3 & ERS1 & ERS37 \\
\hline $\mathrm{SiO}_{2}$ & 63.68 & 64.30 & 63.93 & 64.72 & 64.86 & 64.95 & 64.75 \\
\hline $\mathrm{Al}_{2} \mathrm{O}_{3}$ & 18.62 & 18.56 & 18.82 & 18.71 & 18.66 & 18.9 & 18.9 \\
\hline $\mathrm{TiO}_{2}$ & 0.00 & 0.00 & 0.04 & 0.00 & 0.03 & 0.03 & 0.04 \\
\hline $\mathrm{FeO}$ & 0.18 & 0.14 & 0.18 & 0.10 & 0.15 & 0.16 & 0.21 \\
\hline $\mathrm{MgO}$ & 0.00 & 0.00 & 0.00 & 0.00 & 0.01 & 0.01 & 0.02 \\
\hline $\mathrm{CaO}$ & 0.01 & 0.01 & 0.01 & 0.02 & 0.01 & 0.01 & 0.02 \\
\hline $\mathrm{Na}_{2} \mathrm{O}$ & 1.65 & 1.64 & 1.72 & 1.70 & 2.83 & 3.03 & 2.95 \\
\hline $\mathrm{K}_{2} \mathrm{O}$ & 14.01 & 14.32 & 13.97 & 13.85 & 12.26 & 12.13 & 12.1 \\
\hline $\mathrm{BaO}$ & 0.83 & 0.60 & 0.86 & 0.55 & 1.23 & 1.25 & 1.46 \\
\hline $\mathrm{SrO}$ & 0.18 & 0.05 & 0.14 & 0.07 & 0.2 & 0.22 & 0.04 \\
\hline $\mathrm{Rb}_{2} \mathrm{O}$ & 0.03 & 0.05 & 0.05 & 0.05 & $\mathrm{n} / \mathrm{a}$ & $\mathrm{n} / \mathrm{a}$ & $\mathrm{n} / \mathrm{a}$ \\
\hline$\Sigma$ & 99.181 & 99.686 & 99.722 & 99.775 & 100.23 & 100.7 & 100.49 \\
\hline
\end{tabular}

V5, V14, V16 and V22 are samples of the sanidine from Volkesfeld. Samples ERN3, ERS1 and ERS37 are sanidines from Rockeskyll, they were analzed by Demtröder (ms, 2011) at the Ruhr-University Bochum.

$X_{\text {Or }} \leq 0.99$. We use two different sanidines from the Eifel with initial compositions $X_{\mathrm{Or}}=0.72$ and $X_{\mathrm{Or}}=0.84$ so that the entire composition range could be covered while keeping the composition shifts towards more sodium-rich compositions lower than about 10 mole percent and composition shifts towards more potassium-rich compositions lower than about 16 mole percent, so that the mechanical effects associated with chemically induced lattice strain could be minimized. The chemical patterns produced by cation exchange were used for direct determination of the compositional dependence of the interdiffusion coefficient. The theoretical basis for analyzing composition dependent, anisotropic diffusion in a monoclinic crystal is presented in the companion paper by Petrishcheva and others (2014). The results are discussed in the light of earlier determinations and theoretical calculations based on an interdiffusion model for ionic crystals (Manning, 1968).

\section{METHODS}

\section{Starting Materials}

Two gem quality sanidines from the localities Volkesfeld and Rockeskyll from the Eifel (Germany) were used as starting materials. The sanidines from the Eifel are known for their chemical homogeneity and have been well characterized in various studies (Weitz, 1972; Riley and Bailey, 2003; Parsons and Lee, 2005; Demtröder, ms, 2011; Neusser and others, 2012). The chosen crystals are optically clear. The sanidine from Volkesfeld is either colorless or smoky brown in color. The sanidine from Rockeskyll is colorless. Pieces of each feldspar type were analyzed using scanning electron microscopy and electron microprobe analysis. The selected feldspars turned out to be chemically homogenous within the resolution of the applied methods and are free of twins, exsolutions, second phase precipitates, microcracks or any other structural flaws or heterogeneities. Mineral chemical analyses of both feldspars are given in table 1. The initial compositions of the Volkesfeld- and the Rockeskyll sanidines are $O r_{85} A b_{14} C s_{1}$, and $O r_{72} A b_{26} C s_{2}$ (Demtröder, ms, 2011), respectively, with minor iron contents of about 0.1 to 0.2 weight percent FeO. Both feldspars have monoclinic symmetry and crystallized in the space group C2/m. Aluminum and silicon on the tetrahedral site are highly disordered with $\Sigma t_{1}=61$ (Volkesfeld) (Neusser and 
TABLE 2

Temperatures, salt mixtures and run durations for cation exchange experiments

\begin{tabular}{|c|c|c|c|c|}
\hline & $\mathrm{T}\left[{ }^{\circ} \mathrm{C}\right]$ & $X_{K}^{\text {salt }}$ & $X_{O r}^{e q}$ & run duration $[\mathrm{d}]$ \\
\hline \multirow{10}{*}{$\begin{array}{l}\overrightarrow{0} \\
\frac{0}{0} \\
0 \\
0 \\
0 \\
p\end{array}$} & 800 & 0.48 & 0.80 & 32 \\
\hline & 800 & 1.00 & 1.00 & 32 \\
\hline & & 0.30 & 0.70 & $1,2,4,8,16,32,64$ \\
\hline & & 0.35 & 0.92 & 8 \\
\hline & 850 & 0.60 & 0.97 & $1,2,4,8,16,32,64$ \\
\hline & & 0.85 & 0.73 & $1,2,4,8,16,32,64$ \\
\hline & & 1.00 & 1.00 & $1,2,4,8,16,32,64$ \\
\hline & 920 & 1.00 & 1.00 & $1,2,4,8,16$ \\
\hline & 950 & 1.00 & 1.00 & 1,2 \\
\hline & 1000 & 1.00 & 1.00 & 1 \\
\hline \multirow{8}{*}{ 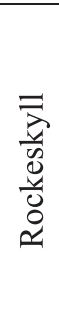 } & & 0.37 & 0.65 & 32 \\
\hline & 800 & 0.55 & 0.80 & 32 \\
\hline & & 0.22 & 0.45 & $4,8,16$ \\
\hline & 850 & 0.50 & 0.85 & $4,8,16$ \\
\hline & & 1.00 & 1.00 & 8 \\
\hline & 920 & 0.50 & 0.82 & 2 \\
\hline & 950 & 0.50 & 0.81 & 1 \\
\hline & 1000 & 0.50 & 0.81 & 1 \\
\hline
\end{tabular}

others, 2012) and $\Sigma t_{1}=0.58-0.62$ (Rockeskyll) (Demtröder, ms, 2011). Although there is no difference in chemical composition or Al-Si-order between the colorless and smoky brown variants of the sanidine from Volkesfeld all samples were prepared from the smoky brown variant to ensure that the starting material is as uniform as possible. The lattice orientations of millimeter-sized pieces of the feldspars were determined on a four-circle goniometer. They were then prepared as polished plates of $3 \times 3 \mathrm{~mm}$ size and $1 \mathrm{~mm}$ thickness with the polished surfaces corresponding to either the $(001)$ or $(010)$ planes of the feldspar.

\section{Exchange Experiments}

For each experiment a single polished plate of sanidine was sealed in a quartz glass tube under vacuum together with a mixture of $\mathrm{NaCl}-\mathrm{KCl}$ (or $\mathrm{NaBr}-\mathrm{KBr}$ for $800{ }^{\circ} \mathrm{C}$ experiments) salts. The plates were pre-polished by hand on a diamond polishing disk, the final polishing was done on a silk polishing cloth with $1 \mu \mathrm{m}$ diamond powder. The salt had a specific potassium mole fraction to produce the desired composition shift in the feldspar through cation exchange. The amount of salt was chosen so that a 40:1 molar proportion of the alkali cations was contained in the salt relative to the feldspar to ensure quasi constant composition of the salt during cation exchange. The sealed tubes were then heated to temperatures between 800 and $1000{ }^{\circ} \mathrm{C}$ in a box furnace at atmospheric pressure. Temperatures were measured with a type $\mathrm{N}$ thermoelement and were accurate within $\pm 1{ }^{\circ} \mathrm{C}$.

Experiments with selected salt concentrations were done for run durations of 1 to 64 days and at temperatures between $850^{\circ} \mathrm{C}$ and $1000^{\circ} \mathrm{C}$ using $\mathrm{NaCl}$ and $\mathrm{KCl}$ salt. For experiments at $800^{\circ} \mathrm{C} \mathrm{NaBr}\left(\mathrm{T}_{\text {melt }}=747^{\circ} \mathrm{C}\right)$ and $\mathrm{KBr}\left(\mathrm{T}_{\text {melt }}=734^{\circ} \mathrm{C}\right)$ salts were used. All experiments are listed in table 2.

The crystal plates retained their surface polish after cation exchange and no indication of surface reaction or recrystallization was found. After exchange the plates 

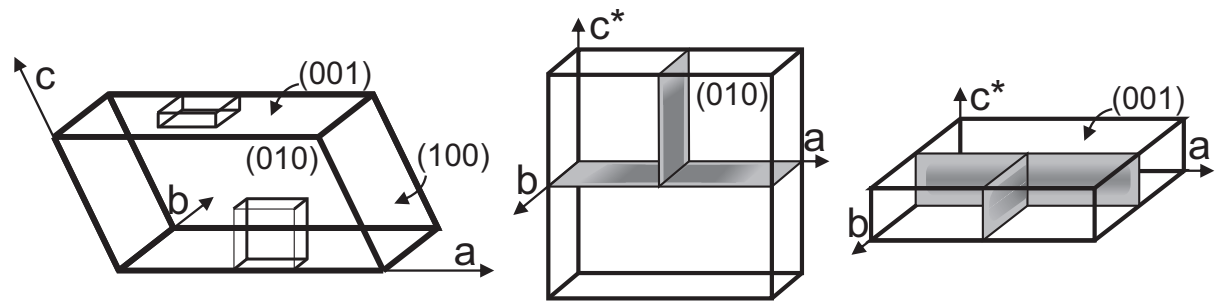

Fig. 1. Left: sketch of feldspar crystal with (100), (010), and (001) faces developed; 3x3x1 mm sized plates with their large faces parallel to $(010)$ or $(001)$ were cut from the feldspar for use in cation exchange experiments; after cation exchange the (010) (middle) and (001) (right) plates were cut in two directions, mounted in resin, ground and polished so that the planes shown in gray are on the polished sample surface ready for EMPA analysis; gray shades schematically indicate chemical alteration of the crystal.

were cut in two mutually perpendicular directions and thick slides were prepared that allowed measurements of concentration profiles in three crystallographic directions (fig. 1). The samples were polished mechanically using diamond paste with decreasing grain sizes down to $0.25 \mu \mathrm{m}$ on polyamide pads. For orientation analysis by electron back-scatter diffraction the samples were additionally polished chemo-mechanically using a colloidal silica suspension (Köstrosol, pH 9.2 to 10), a polyurethane polishing pad and an active rotary head polishing apparatus to ensure a defect free crystal lattice at the immediate sample surface.

\section{Scanning Electron Microscopy and Crystal Orientation Analysis}

The samples were carbon coated using a double carbon-thread at a distance of about $8 \mathrm{~cm}$ from the sample surface under vacuum conditions better than $10^{-5}$ mbar chamber pressure to establish electrical conductivity. BSE imaging was done using an FEI Inspect $S$ scanning electron microscope with a tungsten filament electron source. BSE imaging was done at high contrast settings so that variations in $X_{\text {Or }}$ of a few percent could readily be discerned from changes in the gray shade on BSE images.

For electron backscatter diffraction analysis (EBSD) a thinner carbon coating than for imaging was applied, using only a single carbon thread at the same conditions to establish electrical conductivity. EBSD data were acquired using a FEI Quanta 3D FEG microscope equipped with a field-emission electron source and an EDAX Digiview IV EBSD camera. The sample was tilted to $70^{\circ}$ in order to reach a beam incidence angle of $20^{\circ}$ with respect to the sample surface. The edges of the feldspar crystals were aligned parallel to the $\mathrm{x}$ - and $\mathrm{y}$-directions of the scan reference system by stage rotation. The electron-beam was set to $15 \mathrm{kV}$ accelerating voltage and $4 \mathrm{nA}$ probe current in analytic mode using a SEM aperture of $1 \mathrm{~mm}$. The working distance was between 12 and $14 \mathrm{~mm}$. A 2x2 or 4x4 binning of the EBSD camera-resolution was applied. Hough settings were adjusted for each grain according to the EBSD pattern quality of the grain. Common settings were $1^{\circ}$ theta step size and a minimum peak distance of 8 to $12 \mathrm{~mm}$ for indexing 3 to 20 Hough peaks. A medium (9x9) or large (13x13) convolution mask was applied to the Hough space in order to eliminate artificial peaks and enhance weak bands. Only the interior portion of the EBSD pattern was used for indexing, determined by the $\rho$-fraction of 60 percent to 85 percent. EBSD maps were obtained by beam-scanning across a $40 \times 40 \mu \mathrm{m}$ to $100 \times 100 \mu \mathrm{m}$ sized area using a hexagonal grid at a step size of 10 to $15 \mu \mathrm{m}$. The large step-width was chosen to avoid beam degradation due to the low electron-beam-stability of feldspar. The electron backscatter diffraction patterns were acquired and processed using the software packages OIM Data Collection and Analysis. 10 to 100 data points were collected for each crystal. In case of inconsistent automatic indexing, additional single 
point analyses were performed and indexing statistics were checked in order to identify the correct orientation of the crystal.

\section{Electron Microprobe Analysis}

For testing the homogeneity and determining the initial composition of the starting materials, fragments of several crystals were embedded in epoxy resin and polished. EPMA measurements were done using a CAMECA SX-100 at the Center for Earth Sciences, University of Vienna. The instrument was operated at a high voltage of $15 \mathrm{kV}$ and a beam current of 15 to $20 \mathrm{nA}$. The beam was defocused to $3 \mu \mathrm{m}$ in diameter to minimize the loss of $\mathrm{Na}$ and $\mathrm{K}$ by migration. Mineral chemical analysis of the samples after cation exchange was done using a thermal field emission electron gun JEOL JXA-8500F (Hyperprobe) at the Helmholtzzentrum Potsdam - German Research Centre for Geosciences. Mineral compositions were analyzed along profiles between 15 and $150 \mu \mathrm{m}$ in length with $0.5 \mu \mathrm{m}$ or $1 \mu \mathrm{m}$ step-size, depending on the width and sharpness of the diffusion fronts. The profiles were measured normal to the traces of the surfaces of the exchanged samples (fig. 1). The instrument was operated at an accelerating voltage of $8 \mathrm{kV}$ and at a beam current of $10 \mathrm{nA}$. The beam was defocused to $10 \mu \mathrm{m}$ for calibration and fully focused during measurements. All elements were measured simultaneously. Peak counting times were set to 10 seconds and background counting time to 5 seconds to minimize loss of $\mathrm{Na}$ and $\mathrm{K}$ by migration during measurement. With these settings a lateral resolution of better than $500 \mathrm{~nm}$ could be achieved for mineral chemical analyses.

RESULTS

\section{Diffusion Fronts}

In all experiments the cation exchange between feldspar and $\mathrm{NaCl}-\mathrm{KCl}$ or $\mathrm{NaBr}-\mathrm{KBr}$ salt melt produced a zone chemically altered by diffusion along the surfaces of the feldspar plates. The composition of the chemically altered surface layer was determined by the composition of the salt melt and by the alkali feldspar- salt-melt equilibrium partition coefficient. Different chemical patterns and microstructures evolved during cation exchange depending on whether the composition of the feldspar was shifted towards more sodium-rich or towards more potassium-rich compositions.

For shifts towards more potassium-rich compositions regular, light gray rims are observed on BSE images along the outer edges of the crystal plates (fig. 2). They correspond to the domains within the feldspar that have been enriched in potassium during cation exchange. The potassium-enriched domains propagate further into the interior of the crystal plates with time. Penetration of the potassium into the crystal and concomitant removal of sodium from the crystal interior can only occur by sodiumpotassium interdiffusion on the alkali sublattice of the feldspar. The chemically altered rim and the interior domains with the original composition preserved are separated by more or less sharp transition zones, which will henceforth be referred to as diffusion fronts. From BSE images and chemical profiles measured across the diffusion fronts produced from exchange with pure $\mathrm{KCl}$ melt at $850{ }^{\circ} \mathrm{C}$ it is seen that diffusion fronts are sharp along profiles measured in the direction perpendicular to the (010) plane and comparatively broad in profiles measured along the direction perpendicular to the (001) plane (fig. 2). It is interesting to note that sharp diffusion fronts in the direction perpendicular to (010) only occur if the feldspar composition is shifted to potassium mole fractions in excess of 0.95 . If the composition shift is less, the fronts are comparatively broad (see fig. 3).

Identifying the position of the diffusion fronts by the position of the inflection point in the composition profile and plotting the front-position relative to the grain 


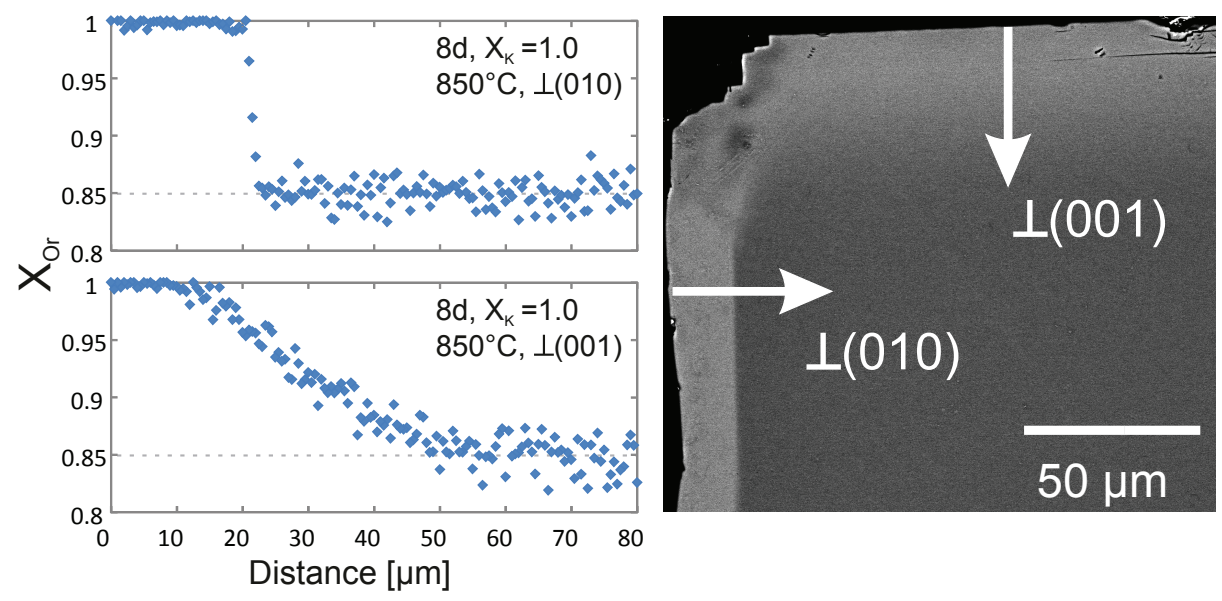

Fig. 2. Composition-distance data and corresponding BSE image obtained from Volkesfeld sanidine after a composition shift towards $X_{\text {Or }}=1.0$ at $850{ }^{\circ} \mathrm{C}$ : top: profile perpendicular to $(010)$ typically shows a sharp composition front; bottom: profile perpendicular to (001) typically shows a broad composition front; dotted horizontal lines indicate the original composition of the sanidine $X_{\mathrm{Or}}=0.85$.

surface versus the square root of time yields a linear trend (fig. 4), as is expected for diffusion controlled cation exchange. It is interesting to note that the rate of front propagation is somewhat slower in the direction perpendicular to $(010)$ than perpendicular to (001).

For shifts towards more sodium-rich compositions a gradual change in composition from the fully exchanged surface towards the grain interior is observed, irrespective of the crystallographic direction. The composition profiles do not show an inflection point. For composition shifts towards more sodium-rich compositions of

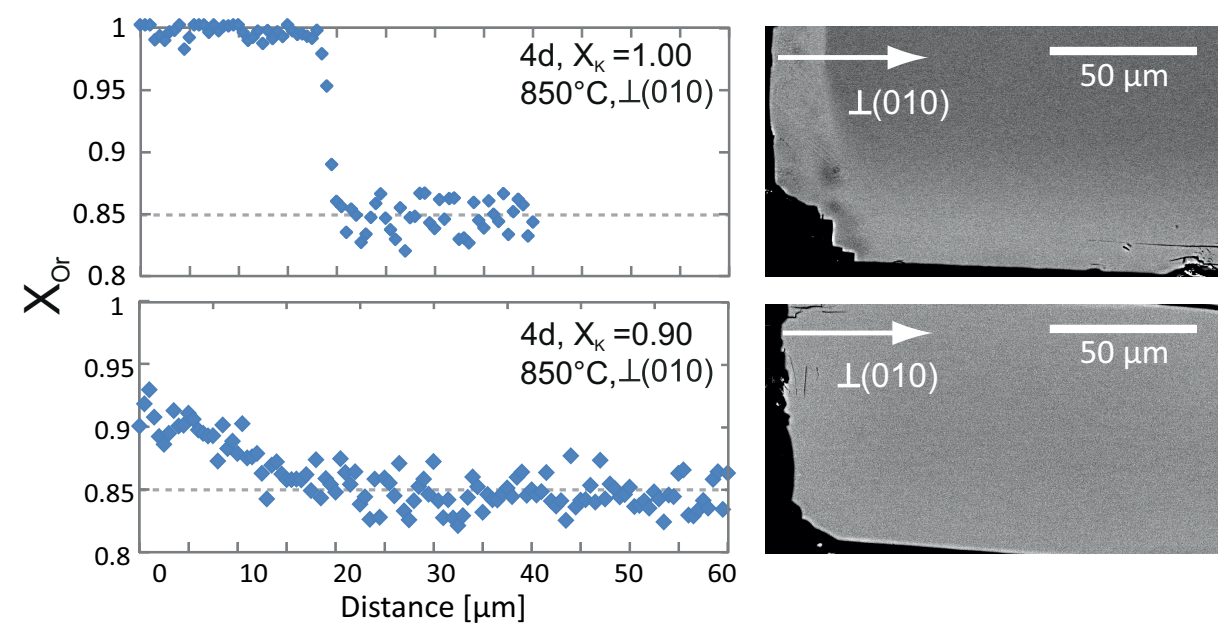

Fig. 3. Composition-distance data and corresponding BSE images obtained from Volkesfeld sanidine after cation exchange; both profiles were taken parallel to the crystallographic $b$-direction top: shift to $X_{\mathrm{Or}}=$ 1.0 produces a sharp composition front; bottom: shift to $X_{\mathrm{Or}}=0.90$ produces a comparatively broad front; white arrows on BSE images indicate position and orientation of the profiles; dotted horizontal lines indicate the original composition of the sanidine $X_{\mathrm{Or}}=0.85$. 

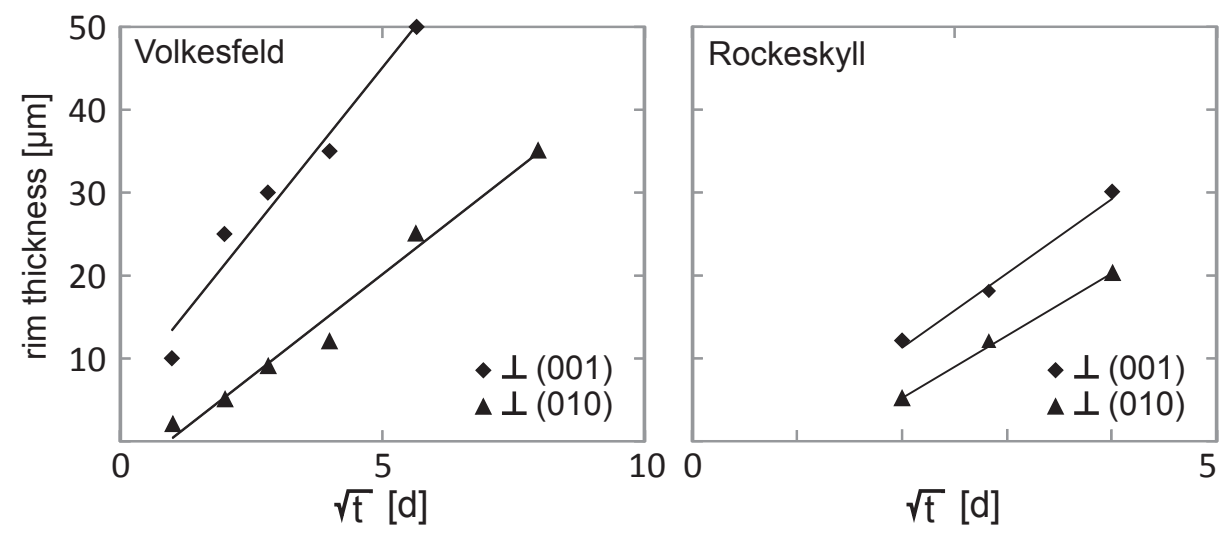

Fig. 4. Thickness of the chemically altered surface layer for shifts towards more potassium-rich compositions versus $\sqrt{t}$; data for $850^{\circ} \mathrm{C}$.

more than about 10 mole percent the development of a system of parallel cracks is observed. This is due to the pronounced compositional dependence of the lattice parameters of alkali feldspar. The chemically induced changes in the lattice parameters are about five times larger in the crystallographic $a$-direction than in the $b$-and $c$-directions (Kroll and others 1986; Angel and others, 2012). Any compositional heterogeneity in a single crystal of alkali feldspar produces coherency strain and associated elastic stress. If the chemically induced stress becomes larger than some critical value, fracturing occurs. The fracturing produced by cation exchange and the chemical shift of alkali feldspar towards more sodium-rich compositions were analyzed in detail by Neusser and others (2012) and Scheidl and others (2014). The latter authors showed that the salt melt penetrated into the interior of the crystal plates along the cracks, and chemical alteration also extended from the crack walls into the feldspar crystal producing complex chemical patterns. Actually, in some exchange experiments with pure $\mathrm{KCl}$ melt, that is, for composition shifts towards more potassium-rich composition, cracks, albeit with a complex geometry, were also observed (Schäffer and others, 2014). In the analysis of sodium-potassium interdiffusion that follows we avoided such cracks and their composition haloes in order to keep the diffusion problem one-dimensional. The presence of unobserved cracks within the activation volume during analysis can of course not be completely ruled out but due to the small size of the activation volume and the geometry of the cracks we are reasonably certain that the majority of our analyses are uninfluenced by cracks.

\section{Extraction of the Na-K Interdiffuson Coefficient}

Given the 40-fold molar excess of the alkali cations contained in the salt-melt as compared to the alkali cations contained in the feldspar, the composition of the melt remains practically constant during cation exchange implying a constant $\mathrm{Na} / \mathrm{K}$ ratio at the crystal surface. In the light of this boundary condition, the geometry of the mole fraction profiles, in particular the existence of inflection points in the mole fraction profiles obtained for shifts towards potassium-rich compositions with $X_{\mathrm{Or}} \geq 0.95$, point to a compositional dependence of the sodium-potassium interdiffusion coefficient (Crank, 1975; Petrishcheva and others, 2014). When extracting the sodium-potassium interdiffusion coefficient from the concentration-distance data, the concentration dependent nature of the interdiffusion process must be accounted for. A technique for integrating the diffusion equation with a composition dependent diffusion coefficient 
was developed by Boltzmann (1894). It has been adapted for application to the specific initial and boundary conditions corresponding to the experimental setting of our cation exchange experiments in the companion paper by Petrishcheva and others (2014). The calculation procedure is briefly summarized below; a derivation is given in Petrishcheva and others (2014). We consider diffusion only in the directions perpendicular to the (001) and to the (010) surfaces of the crystal plates. The profiles were all taken at sufficiently large distances from the edges of the crystal plates and from cracks so that complexities of the chemical patterns were avoided. The diffusion process underlying the observed composition profiles can then be treated as strictly onedimensional. The basic equation for obtaining the composition dependent sodiumpotassium interdiffusion coefficient then reads (Petrishcheva and others, 2014)

$$
D(c)=-2 \frac{d \eta}{d c} \int_{c 2}^{c} \eta(c) d c,
$$

where $\mathrm{c}$ is a shorthand notation for $X_{\mathrm{Or}}, c_{2}$ is the initial bulk mole fraction in the feldspar crystal and

$$
\eta=\frac{x}{2 \sqrt{t}} \text { defined for } t>0
$$

is Boltzmann's similarity variable combining the space variable $x$ and time $t$ into a single variable.

The procedure of extracting $D_{\mathrm{NaK}}(c)$ involved two steps. In a first step $\eta=$ $x /(2 \sqrt{ } t)$ was calculated for each mole fraction profile, which was then recast in the form $c(\eta)$ and smoothed. In a second step, the inverse function $\eta(c)$ was inserted into equation (1) to obtain $D_{\mathrm{NaK}}(c)$. The validity of the analysis was tested by back modeling of the diffusion using the extracted sodium-potassium interdiffusion coefficient, which generally gave perfect agreement between calculated and experimentally observed mole fraction profiles (see also Petrishcheva and others, 2014).

Smooth mole fraction profiles without sharp diffusion fronts yield a nearly constant sodium-potassium interdiffusion coefficient. In this case the interdiffusion coefficient can also be obtained by fitting to the well known error-function solution for diffusion into a semi-infinite half-space with a constant concentration on the boundary and a constant diffusion coefficient (Crank, 1975). Both approaches indicate that the compositional dependence of $D_{\mathrm{NaK}}$ is minute for $c<0.95$, see figure 5 . On the other hand, to explain the observed steep fronts developing for composition shifts to high-potassium mole fractions with $X_{\mathrm{Or}} \geq 0.95$ it is crucial to account for the quick increase of $D_{\mathrm{NaK}}(\boldsymbol{c})$ as $c$ approaches 1 . This increase is quantified by equation (1). These results are discussed in more detail in the next section.

\section{Composition and Temperature Dependence of the Sodium-Potassium Interdiffusion Coefficient}

The compositional dependence of the interdiffusion coefficient was extracted for the composition interval $0.65<X_{\mathrm{Or}}<0.99$, for the directions normal to (001) and normal to (010), for temperatures between 800 and $1000{ }^{\circ} \mathrm{C}$, and for run durations between 1 and 64 days (see fig. 5).

The sodium-potassium interdiffusion coefficient has little or no compositional dependence over most of the composition range of $0.65 \leq X_{\mathrm{Or}} \leq 0.95$. At very potassium-rich compositions of $X_{\mathrm{Or}} \geq 0.95$ it shows a substantial increase with increasing $X_{\mathrm{Or}}$. The increase in $D_{\mathrm{NaK}}$ towards the potassium end-member composition of the alkali feldspar is observed in both the directions perpendicular to (010) and perpendicular to (001). The increase is, however, more abrupt and more localized in 

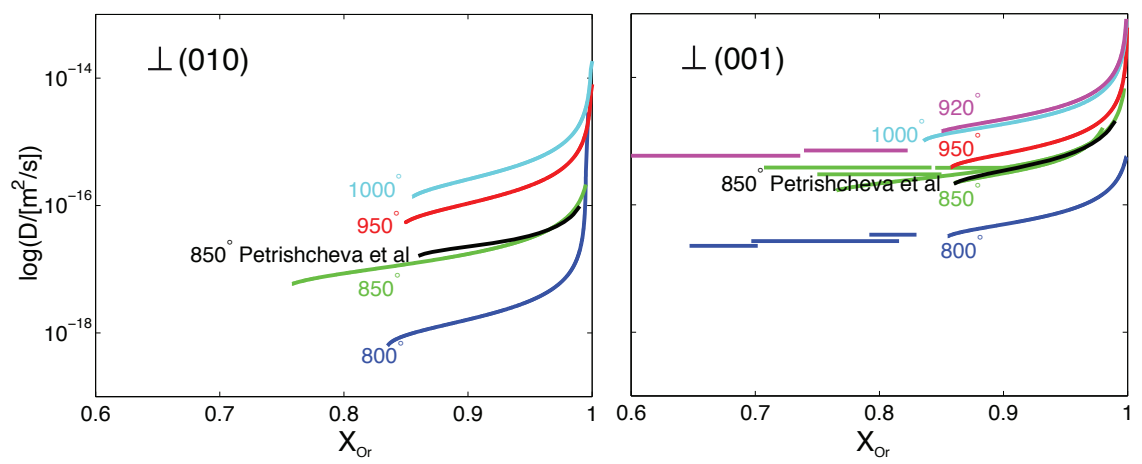

Fig. 5. Compositional dependence of $D_{\mathrm{NaK}}$ at $800^{\circ} \mathrm{C}, 850{ }^{\circ} \mathrm{C}, 920^{\circ} \mathrm{C}, 950{ }^{\circ} \mathrm{C}$, and $1000^{\circ} \mathrm{C}$.

composition in the direction perpendicular to (010) than perpendicular to (001). It is also seen that for the entire composition range sodium-potassium interdiffusion is faster normal to (001) than normal to (010).

Similar trends are observed at all temperatures considered in this study. For a given composition $D_{\mathrm{NaK}}$ increases with temperature with the only exception at $920^{\circ} \mathrm{C}$. The interdiffusion coefficient extracted from experiments at $920{ }^{\circ} \mathrm{C}$ is much higher than would be expected, exceeding the values for $950{ }^{\circ} \mathrm{C}$ and even $1000{ }^{\circ} \mathrm{C}$. Similar results being obtained from several, separately conducted experiments, indicated that this is not the effect of faulty measurements or preparation. The higher than expected values may be an effect of the changes of physical properties documented for Eifel sanidine in this temperature range (Bertelmann and others, 1985; Demtröder, ms, 2011), the implications of which for sodium-potassium interdiffusion are not known to date. As it is stated in literature that the changes are irreversible, two plates of Volkesfeld sanidine with polished (010) surfaces were tempered at $1050{ }^{\circ} \mathrm{C}$ for four days and cooled down very slowly. Subsequently they were exchanged at $850{ }^{\circ} \mathrm{C}$ for 8 days and shifted to $X_{\mathrm{Or}} 1.0$ and 0.73 , respectively, to test if the anomalous behavior has an influence on the overall processes of diffusion. The resulting diffusion profiles were identical to those observed in un-tempered samples. Thus, if the anomaly known for Eifel sanidines has an influence, it seems to be limited to the temperature range of the actual changes to the optical properties. Further experiments beyond the scope of this study would be needed to investigate this further.

In the following we use the experimental data obtained at $800{ }^{\circ} \mathrm{C}, 950{ }^{\circ} \mathrm{C}$, and $1000{ }^{\circ} \mathrm{C}$ to extract the parameters of the Arrhenius equation

$$
\begin{aligned}
& D_{\text {NaK }}=D_{0} \operatorname{Exp}\left(-\frac{E_{A}}{R T}\right), \text { where } \\
& D_{0}^{\perp(001)}(0.92)=5.18 \cdot 10^{-8} \mathrm{~m}^{2} / \mathrm{s}, \quad \mathrm{E}_{A}^{\perp(001)}(0.92)=179 \mathrm{~kJ} / \mathrm{mole} \\
& D_{0}^{\perp(001)}(0.98)=1.82 \cdot 10^{-7} \mathrm{~m}^{2} / \mathrm{s}, \quad \mathrm{E}_{A}^{\perp(001)}(0.98)=182 \mathrm{~kJ} / \mathrm{mole} \\
& D_{0}^{\perp(010)}(0.92)=5.81 \cdot 10^{-5} \mathrm{~m}^{2} / \mathrm{s}, \quad \mathrm{E}_{A}^{\perp(010)}(0.92)=272 \mathrm{~kJ} / \mathrm{mole} \\
& D_{0}^{\perp(010)}(0.98)=1.34 \cdot 10^{-4} \mathrm{~m}^{2} / \mathrm{s}, \quad \mathrm{E}_{A}^{\perp(010)}(0.98)=269 \mathrm{~kJ} / \mathrm{mole}
\end{aligned}
$$

The corresponding Arrhenius diagram is shown in figure 6, the interdiffusion coefficients are found in table 3 . 


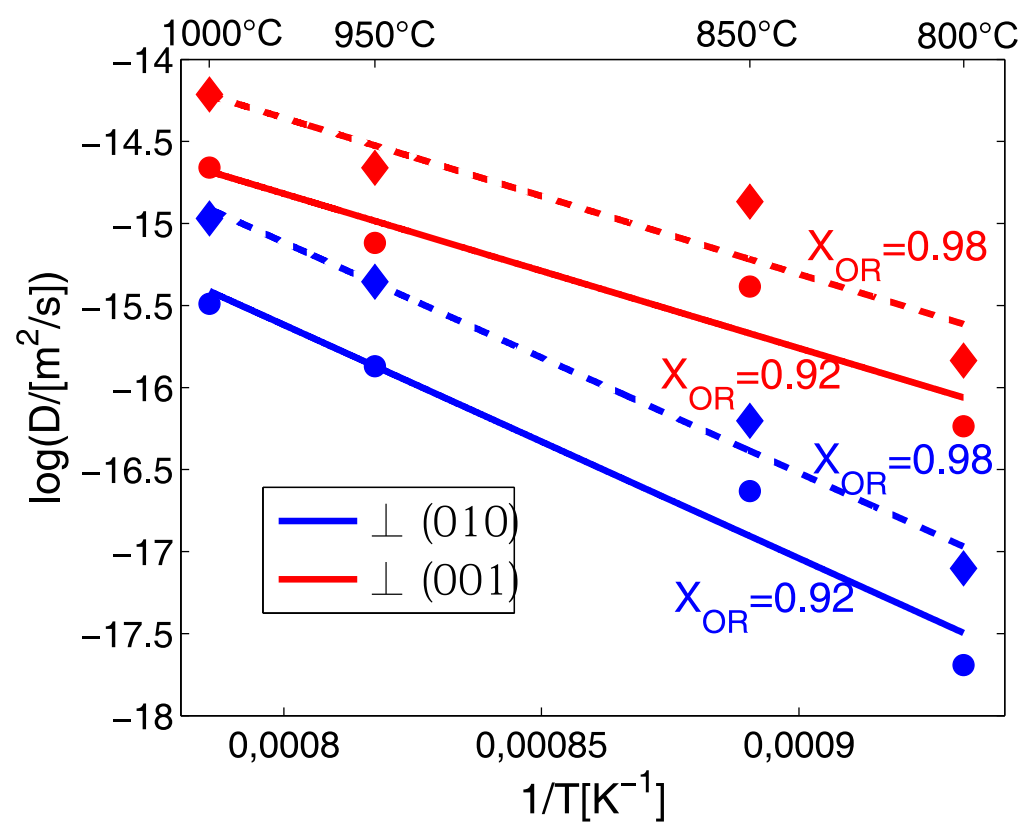

Fig. 6. Temperature dependence of $D_{\mathrm{NaK}}$ for directions perpendicular to (001) and perpendicular to (010) and for two compositions.

\section{DISCUSSION}

Our findings from the cation exchange experiments can be summarized as follows: (1) sodium-potassium interdiffusion is markedly composition dependent at $X_{\mathrm{Or}} \geq 0.95$. (2) In contrast, the compositional dependence of $D_{\mathrm{NaK}}$ is minute or entirely absent in the composition range $0.65 \leq X_{\mathrm{Or}} \leq 0.95$. (3) For all compositions sodium-potassium interdiffusion is slower in the direction perpendicular to $(010)$ than in the direction perpendicular to (001). (4) This behavior is found at all temperatures from $800{ }^{\circ} \mathrm{C}$ to $1000^{\circ} \mathrm{C}$.

A compositional dependence of $D_{\mathrm{NaK}}$ was already found in earlier studies (Petrović, 1972; Christoffersen and others, 1983; Petrishcheva and others, 2014). Using albite with $X_{\mathrm{Or}}=0.00$ and orthoclase with $X_{\mathrm{Or}}=0.86$ in cation exchange experiments Petrović (1972) observed that $D_{\mathrm{NaK}}$ was independent of composition in the composi-

TABLE 3

Interdiffusion coefficients in $\left[\mathrm{m}^{2} / \mathrm{s}\right]$ for Volkesfeld sanidine in the directions perpendicular to (001) and perpendicular to (010) for two compositions

\begin{tabular}{cccccc}
\hline & \multicolumn{2}{c}{$\perp(001)$} & \multicolumn{2}{c}{$\perp(010)$} \\
\hline & $X_{O r}$ & 0.92 & 0.98 & 0.92 & 0.98 \\
\hline \hline & 800 & $5.80 \times 10^{-17}$ & $1.46 \times 10^{-16}$ & $2.03 \times 10^{-18}$ & $7.90 \times 10^{-18}$ \\
$\circlearrowright$ & 850 & $4.12 \times 10^{-16}$ & $1.36 \times 10^{-15}$ & $2.33 \times 10^{-17}$ & $6.26 \times 10^{-17}$ \\
$\stackrel{\Xi}{\circ}$ & 920 & $2.62 \times 10^{-15}$ & $7.38 \times 10^{-15}$ & & \\
& 950 & $7.62 \times 10^{-16}$ & $2.19 \times 10^{-15}$ & $1.35 \times 10^{-16}$ & $4.41 \times 10^{-16}$ \\
& 1000 & $2.19 \times 10^{-15}$ & $6.12 \times 10^{-15}$ & $3.24 \times 10^{-16}$ & $1.07 \times 10^{-15}$ \\
\hline
\end{tabular}




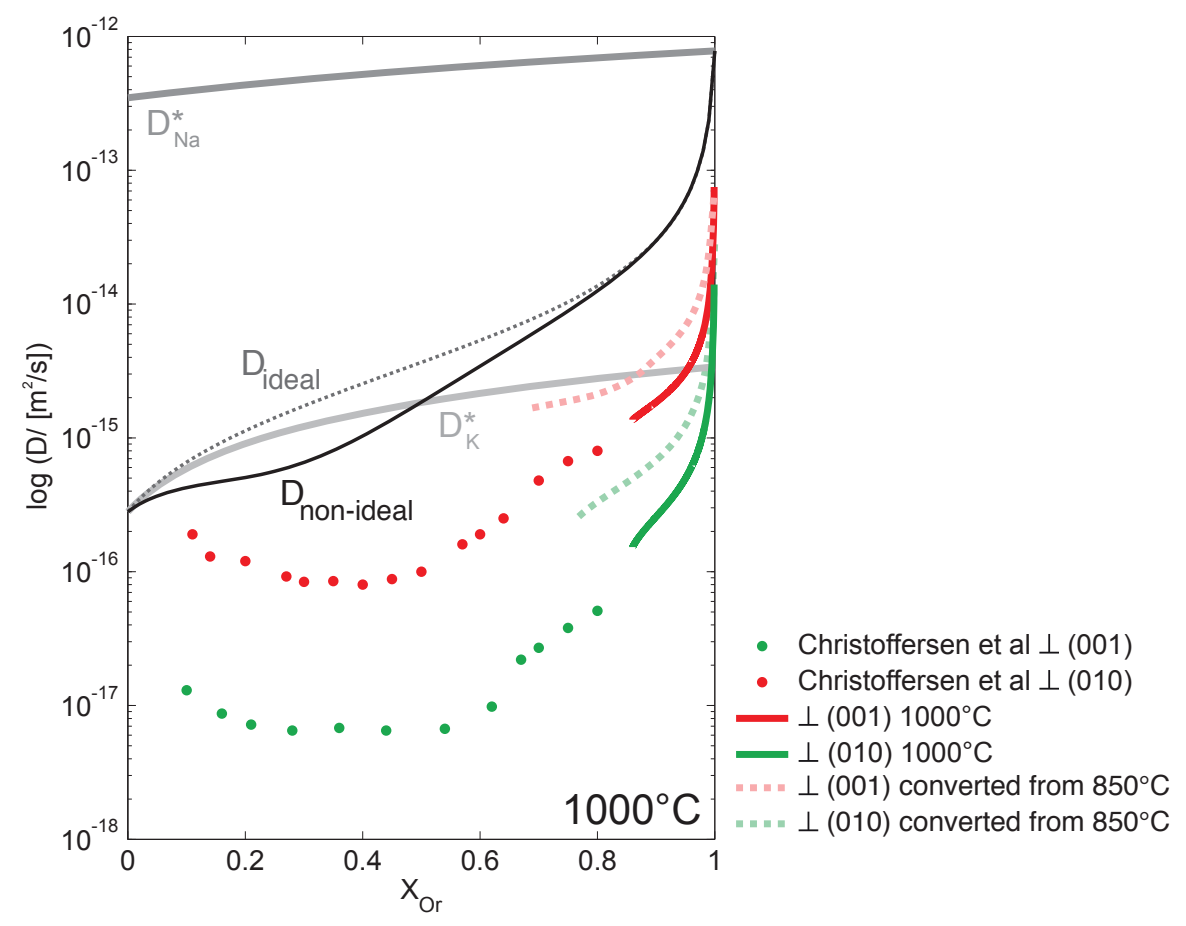

Fig. 7. Comparison of our experimental results with a theoretical interdiffusion model based on the Nernst-Planck equation, and with literature data by Christoffersen and others (1983); the theoretical values were calculated using tracer-diffusion coefficients for Na and K determined by Foland (1974) and Kasper (1975).

tion range $0.00 \leq X_{\mathrm{Or}} \leq 0.1$ whereas a pronounced compositional dependence was observed for potassium-rich compositions with $X_{\mathrm{Or}} \geq 0.86$.

In the study by Christoffersen and others (1983) classical diffusion couples were used, which were comprised of albite and adularia single crystals put into contact at a polished interface. During annealing at $900{ }^{\circ} \mathrm{C}$ and $1000{ }^{\circ} \mathrm{C}$ the initial compositional difference across the albite-adularia contact degraded by $\mathrm{Na}^{+}-\mathrm{K}^{+}$cation exchange between the two crystals, producing a sigmoidal mole fraction profile. The classical Boltzmann-Matano analysis was used for extracting the composition dependent $D_{\mathrm{NaK}}$ in the composition range $0.10 \leq X_{\mathrm{Or}} \leq 0.80$. A minimum was found in $D_{\mathrm{NaK}}$ at $X_{\mathrm{Or}} \approx$ 0.4 and an increase by a factor of 2.5 towards $X_{\text {Or }}=0.1$ as well as an increase by a factor of about 10 towards $X_{\text {Or }}=0.8$ (fig. 7). The analysis of our $1000{ }^{\circ} \mathrm{C}$ experiments yields $D_{\mathrm{NaK}}(c)$ which extends the earlier determinations by Christoffersen and others (1983) to higher $X_{\mathrm{Or}}$ without any apparent jump for both the direction perpendicular to $(010)$ and the direction perpendicular to (001) (fig. 7). As our $850{ }^{\circ} \mathrm{C}$ experiments extend over a wider composition range we re-calculated them for $1000^{\circ} \mathrm{C}$ using the activation energies determined from our experiments (dashed curves in fig. 7). The recalculated values plot somewhat higher than the data measured at $1000{ }^{\circ} \mathrm{C}$. In the overlapping composition range $0.7 \leq X_{\mathrm{Or}} \leq 0.8$, where we observe only minor compositional dependence of $D_{\mathrm{NaK}}$, our data deviates from those of Christoffersen and others (1983), who observed a more pronounced compositional dependence.

Actually a strong increase in $D_{\mathrm{NaK}}(c)$ similar to what we observe in our experiments is predicted from the model for substitutional interdiffusion in an ionic crystal 
as given by Manning (1968), when the self-diffusion of sodium is assumed to be significantly faster than that of potassium; based on existing literature data this assumption can be safely made. For the case of sodium potassium interdiffusion in alkali feldspar this reads

$$
D_{N a K}=\frac{D_{N a}^{*}(c) D_{K}^{*}(c)}{(1-c) D_{N a}^{*}(c)+c D_{K}^{*}(c)}\left[1+\frac{\partial \ln \gamma_{O r}}{\partial \ln c}\right],
$$

where $D_{N a}^{*}(c)$ and $D_{K}^{*}(c)$ are the sodium and the potassium self-diffusion coefficients, respectively, which are considered as composition dependent, and $\gamma_{O r}$ is the activity coefficient of the orthoclase phase component in the alkali feldspar solid-solution.

Figure 7 shows theoretical calculations based on equation 3 in comparison with the directly determined values of $D_{\mathrm{NaK}}(c)$ from this study and from Christoffersen and others (1983). There is reasonable qualitative agreement between our direct determinations of $D_{\mathrm{NaK}}(c)$ for diffusion in the directions perpendicular to (001) and perpendicular to (010) and the theoretical calculations. Our direct determinations indicate, however, slower sodium-potassium interdiffusion by a factor of about five to ten than calculated theoretically for diffusion perpendicular to (001) and slower by almost two orders of magnitude for diffusion in the direction perpendicular to $(010)$. The same trend was observed by Christoffersen and others (1983), however, their values deviate even more significantly from those predicted for more sodium-rich compositions, which were not covered in our experiments. These discrepancies in absolute numbers are probably due to the fact that the $\mathrm{Na}$ - and $\mathrm{K}$ - tracer-diffusion coefficients that were inserted into equation 3 for constructing the diagram in figure 7 were determined using bulk exchange experiments. For the sodium-rich composition both $D_{\mathrm{Na}}^{*}$ and $D_{K}^{*}$ were taken from Kasper (ms, 1975), and for the potassium rich composition both $D_{N a}^{*}$ and $D_{K}^{*}$ were taken from Foland (1974). In these studies carefully sized fragments of natural orthoclase $\left(X_{\mathrm{Or}}=0.94\right)$ and albite $\left(X_{\mathrm{Or}}=0.01\right)$, were exchanged with a ${ }^{41} \mathrm{KCl}$ ${ }^{22} \mathrm{NaCl}$ aqueous solution, the composition of which was chosen to ensure chemical equilibrium between the feldspar and the solution so that measured bulk isotope exchange could safely be ascribed to diffusion rather than dissolution re-precipitation. To account for potential diffusion anisotropy the diffusion coefficients were calculated assuming cylindrical geometry. By this method slow diffusion in one direction $(\perp(010)$ - corresponding to the cylinder axis) and fast diffusion in the plane perpendicular to this direction (that is, in the (010) plane) can be taken into consideration. It was argued by Petrović (1973) that sodium-potassium interdiffusion is isotropic within the (010) plane of alkali feldspar. Recent findings by Petrishcheva and others (2014) revealed, however, a pronounced anisotropy of sodium-potassium interdiffusion within the (010) plane of alkali feldspar. It is thus well possible that the determinations of the tracer-diffusion coefficients by bulk exchange (Foland, 1974; Kasper, ms, 1975) were biased by the contribution of diffusion in the fastest direction. The theoretically calculated $D_{\mathrm{NaK}}(c)$ thus probably corresponds to diffusion in the fastest direction, which is parallel to the [101] direction (Petrishcheva and others, 2014). The $D_{\mathrm{NaK}}^{\perp{ }^{(001)}}(c)$ and $D_{\mathrm{NaK}}^{\perp{ }^{(010)}}(c)$ are thus expected to be slower than this theoretically calculated interdiffusion coefficient, which is in line with the relations shown in figure 7.

It must be noted that a reasonable qualitative agreement between the direct determinations of $D_{\mathrm{NaK}}$ which were conducted by Christoffersen and others (1983) and in our study, with the predictions obtained from the interdiffusion model in equation (3) is only obtained, if the data for the tracer-diffusion coefficients $D_{\mathrm{Na}}^{*}$ and $D_{K}^{*}$ are taken from Kasper (ms, 1975) for sodium-rich compositions and from Foland (1974) for potassium-rich compositions. There are several other determinations of $D_{N a}^{*}$ and $D_{K}^{*}$ available in the literature (see fig. 8). For constructing the diagram in figure 7 the choice of the self-diffusion coefficients was made such that $D_{N a}^{*}(c) \gg D_{K}^{*}(c)$. At 
potassium-rich compositions of the alkali feldspar $D_{\mathrm{NaK}}$ approaches $D_{\mathrm{Na}}^{*}(c)$ (see eq. 3), and this choice of the tracer-diffusion coefficients produces the strong increase in the calculated $D_{\mathrm{NaK}}(c)$ towards potassium end-member composition. This choice of the tracer-diffusion coefficients combined with the non-ideality of the alkali-feldspar solid-solution also produces the pronounced compositional dependence of $D_{\mathrm{NaK}}$ at intermediate compositions with the minimum of $D_{\mathrm{NaK}}(c)$ at a composition of $X_{\mathrm{Or}} \approx 0.4$ as observed by Christoffersen and others (1983). In the composition range $0.65 \leq X_{\mathrm{Or}}$ $\leq 0.80$ the trends in $D_{\mathrm{NaK}}(c)$ derived from our direct determinations are, however, different from the trends obtained from the direct determinations of Christoffersen and others (1983) and also from what is predicted based on equation 3 using the tracer-diffusion coefficients from Kasper (ms, 1975) and Foland (1974). In particular, we find a minute or no compositional dependence of $D_{\mathrm{NaK}}$ in this composition range, whereas a substantial increase of $D_{\mathrm{NaK}}$ with increasing $X_{\mathrm{Or}}$ is documented in the study of Christoffersen and others (1983) and is also predicted theoretically. A $D_{\mathrm{NaK}}$ which is independent of composition would be predicted from equation 3 , if $D_{N a}^{*} \approx D_{K}^{*} \approx$ constant. Such a situation, would, however, not predict the pronounced increase of $D_{\mathrm{NaK}}$ in the composition range of $0.95 \leq X_{\mathrm{Or}} \leq 1.00$. In the light of this apparent incommensurateness between theoretical predictions and direct determinations we speculate about the presence of two different sodium species that may contribute to sodium-potassium interdiffusion in alkali feldspar. Due to its relatively small ionic radius, $\mathrm{Na}^{+}$may occupy interstitial positions (Behrens and others, 1990; Giletti and Shanahan, 1997). On the one hand, such interstitial $\mathrm{Na}^{+}$could charge-balance vacancies on the regular alkali lattice sites, and by this mechanism it could foster vacancy formation on the alkali sublattice and thus enhance sodium-potassium interdiffusion by the vacancy mechanism. On the other hand, the interstitial $\mathrm{Na}^{+}$could make a fast diffusing Na-species by an interstitial mechanism (Petrović, 1972; Christoffersen and others, 1983; Giletti and Shanahan, 1997). The total concentrations of such interstitial $\mathrm{Na}^{+}$is probably very low, irrespective of the composition of the alkali feldspar. Towards high $X_{\text {Or }}$, when the total sodium-concentration in the feldspar becomes low, the interstitial $\mathrm{Na}^{+}$may form a substantial fraction of the total sodium contained in the feldspar. By this mechanism the self-diffusion of sodium would increase appreciably towards high potassium mole fraction in the alkali feldspar, and a concomitant rise of $D_{\mathrm{NaK}}$ would result. It may be argued based on the crystal structure (Petrovic, 1972; Jones and others, 2004) that a vacancy mechanism is indispensable for diffusion in the direction perpendicular to (010). In contrast, within the (010) plane an interstitial mechanism may operate in addition to the vacancy mechanism. This may explain the different degrees of localization of the rise of $D_{\mathrm{NaK}}$ at potassium-rich compositions and the different sharpness of the diffusion fronts in the directions perpendicular to (001) and (010).

In the intermediate composition range substitutional interdiffusion on regular sites of the alkali sub-lattice is probably the main diffusion mechanism. Cation vacancies are an indispensable pre-requisite for substitutional interdiffusion to operate (Mehrer, 2007). Apart from the thermally induced point defects extrinsic defects such as heterovalent substitutions may provide additional vacancies (Mehrer, 2007). In this context the difference in the barium contents between the sanidine from Volkesfeld $\left(0.01 \mathrm{Ba}^{2+}\right.$ a.p.f.u. $)$ and from Rockeskyll $\left(0.02 \mathrm{Ba}^{2+}\right.$ a.p.f.u. $)$ may be worth considering. The $\mathrm{Ba}^{2+}$ may be charge-balanced by cation vacancies in the alkali sub-lattice, and sodium-potassium interdiffusion may be expected to be enhanced in the sanidine from Rockeskyll as compared to the sanidine from Volkesfeld. Such an effect was, however, not observed systematically in our experiments. Earlier workers found that diffusion in the direction perpendicular to (010) is slower than within the $(010)$ plane (Petrović, 1972; Christoffersen and others, 1983). In the companion paper by Petrishcheva and 
others (2014) the full diffusivity tensor and its compositional dependence in the range $0.85 \leq X_{\text {Or }} \leq 1.00$ was determined. These latter authors found similar differences between the rates of sodium-potassium interdiffusion in the directions perpendicular to (001) and (010) as Christoffersen and others (1983), and in addition they documented a diffusion anisotropy also within the $(010)$ plane with the fastest diffusion in the [101] direction and slowest diffusion in the direction within the (010) plane and perpendicular to the [101] direction. Our experimental observations are perfectly in line with these earlier studies. We generally find for both starting materials that sodium-potassium interdiffusion in the direction perpendicular to (010), that is, parallel to the crystallographic $b$-axis, is slower by a factor of 5 to 10 than in the direction perpendicular to (001), that is parallel to $c^{*}$. The diffusion anisotropy tends to become smaller towards higher temperatures. This diffusion anisotropy reflects the different ease of atomic jumps within the (010) plane and in the direction perpendicular to (010), which can be argued on crystal-chemical grounds (Petrović, 1972; Jones and others, 2004; Petrishcheva and others, 2014). In addition the diffusion anisotropy may, in part, also be due to the mechanical effects of composition changes associated with sodium-potassium interdiffusion. Due to the compositional dependence of the lattice parameters any composition heterogeneity that exists in a single crystal of alkali feldspar causes a distortion of the lattice and thus coherency stress. This coherency stress is localized within the diffusion front, which may lead to a feedback producing self-sharpening diffusion fronts and an overall retardation of diffusion in the direction perpendicular to (010) (Schäffer and others, 2014). In particular, this is the case for the very narrow fronts perpendicular to $(010)$ whereas no such effect is expected in the direction perpendicular to $(001)$, where the diffusion fronts are comparatively broad.

In figure 8 our direct determinations of $D_{\mathrm{NaK}}$ and those of Christoffersen and others (1983) are compared with experimental determinations of the sodium- and potassium tracer-diffusion coefficients taken from the literature. Although the determinations of the tracer-diffusion coefficients show considerable scatter, it is generally observed that potassium tracer-diffusion is slower than sodium tracer-diffusion. Our determinations of $D_{\mathrm{NaK}}$ are shown as blue [perpendicular to (010)] and red [perpendicular to (001)] lines for $X_{\mathrm{Or}}=0.92$ (solid) and $X_{\mathrm{Or}}=0.98$ (dashed). The pair of green lines shows the corresponding interdiffusion coefficients given by Christoffersen and others (1983). The activation energies that we determined for Na-K interdiffusion are in the range of the activation energies determined for sodium- and potassium tracer-diffusion. In terms of absolute values the determinations of $D_{\mathrm{NaK}}$ by Christoffersen and others, (1983) are in good agreement with our findings, the temperature dependence of $D_{\mathrm{NaK}}$ as reconstructed from the data of the latter authors is however substantially lower than in our experiments.

\section{CONCLUSIONS}

Sodium-potassium interdiffusion in disordered alkali feldspar was quantified by means of cation exchange experiments between gem quality sanidine from the Eifel and $\mathrm{NaCl}-\mathrm{KCl}$ (or $\mathrm{NaBr}-\mathrm{KBr}$ ) salt melt at temperatures from $800{ }^{\circ} \mathrm{C}$ to $1000{ }^{\circ} \mathrm{C}$ and close to ambient pressure. Due to mechanical effects associated with large composition shifts and the limited composition range of homogeneous alkali feldspars $\left(X_{\mathrm{Or}} \geq 0.72\right)$ the sodium-potassium interdiffusion coefficient could only be determined for $X_{\mathrm{Or}} \geq$ 0.65. $D_{\mathrm{NaK}}$ is markedly composition dependent at $X_{\mathrm{Or}} \geq 0.95$. In the composition range $0.95 \leq X_{\mathrm{Or}} \leq 1.00 D_{\mathrm{NaK}}$ increases substantially with increasing $X_{\mathrm{Or}}$. The compositional dependence of $D_{\mathrm{NaK}}$ is, however, minute or entirely absent in the composition range $0.65 \leq X_{\text {Or }} \leq 0.95$.

A pronounced diffusion anisotropy was found at all temperatures from $800{ }^{\circ} \mathrm{C}$ to $1000{ }^{\circ} \mathrm{C}$; for all compositions sodium-potassium interdiffusion is slower in the direction perpendicular to (010) than in the direction perpendicular to (001). Also, the rise in 


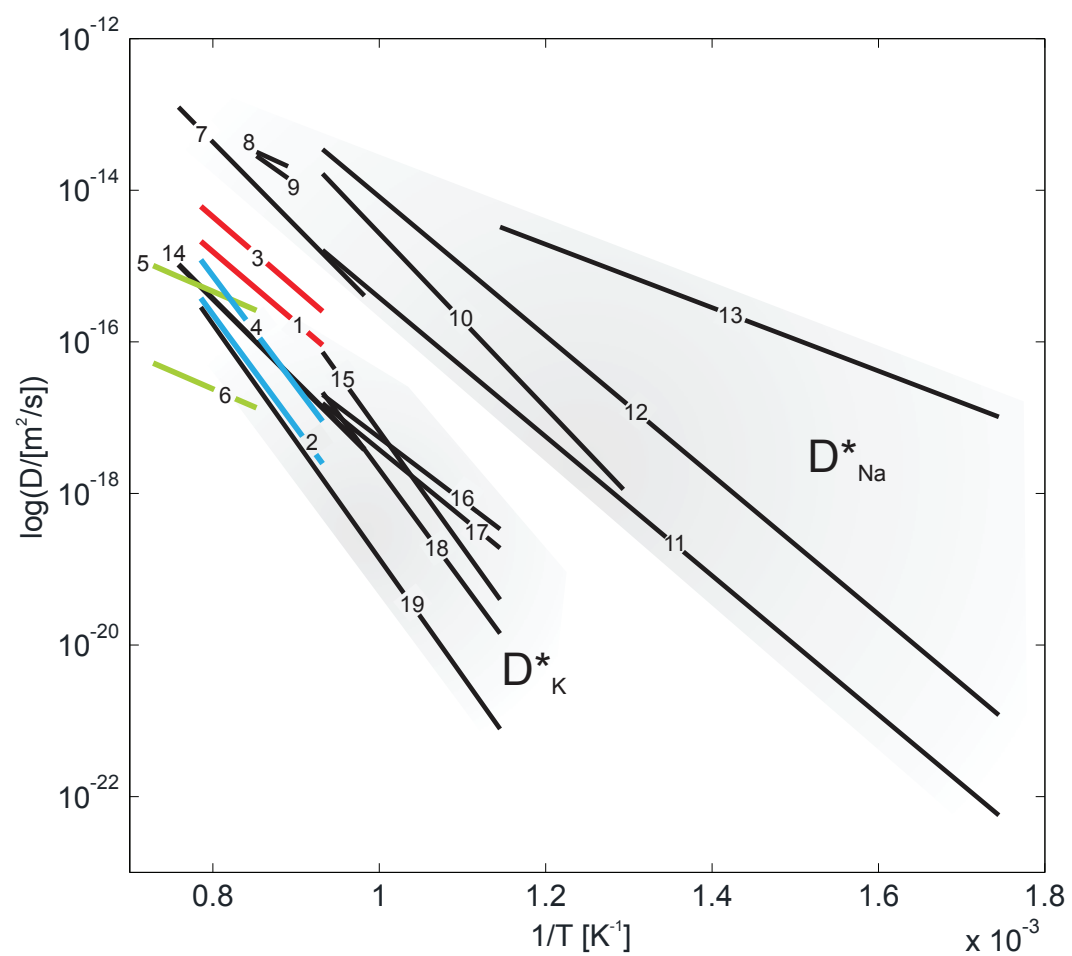

Fig. 8. Arrhenius diagram: $1-D_{\mathrm{Na} / \mathrm{K}}^{\perp(001)}\left(X_{\mathrm{Or}}=0.92\right)-$ this study; $2-D_{\mathrm{Na} / \mathrm{K}}^{\perp(010)}\left(X_{\mathrm{Or}}=0.92\right)-$ this study; 3 $D_{\mathrm{Na} / \mathrm{K}}^{\perp(001)}\left(X_{\mathrm{Or}}=0.98\right)-$ this study; $4-D_{\mathrm{Na} / \mathrm{K}}^{\perp}(010)\left(X_{\mathrm{Or}}=0.98\right)-$ this study; $5-D_{\mathrm{Na} / \mathrm{K}}^{\perp}-$ Christoffersen and others (1983): $6-D_{\mathrm{Na} / \mathrm{K}}^{\perp(010)}-$ Christoffersen and others $(1983) ; 7-D_{N a}^{*}\left(X_{\mathrm{Or}}=0.86\right)-$ Petrović $(1972) 8-D_{N a}^{*}-$ Maury $(1968) ; 9-D_{N a}^{*}-\operatorname{Sippel}(1963) ; 10-D_{N a}^{*}\left(X_{\mathrm{Or}}=0.94\right)$-Foland $(1974) ; 11-D_{N a}^{*}\left(X_{\mathrm{Or}}=0.02\right)-\operatorname{Kasper}(\mathrm{ms}$, $1975) ; 12-D_{N a}^{*}\left(X_{\mathrm{Or}}=0.014\right)-$ Bailey $(1971) ; 13-D_{N a}^{*}\left(X_{\mathrm{Or}}=0.00\right)-$ Lin and Yund $(1972) ; 14-D_{K}^{*}\left(X_{\mathrm{Or}}=\right.$ $0.86)$ - Petrović $(1972) ; 15-D_{K}^{*}\left(X_{\mathrm{Or}}=1.00\right)-\mathrm{Lin}$ and Yund $(1972) ; 16-D_{K}^{*}\left(X_{\mathrm{Or}}=0.014\right)-$ Giletti and others $(1983)(1974) ; 17-D_{K}^{*}\left(X_{\mathrm{Or}}=0.02\right)-$ Kasper $(\mathrm{ms}, 1975) ; 18-D_{K}^{*}\left(X_{\mathrm{Or}}=0.94\right)-$ Foland $(1974) ; 19-D_{K}^{*}$ $\left(X_{\text {Or }}=0.02\right)-$ Giletti and Shanahan (1997).

$D_{\mathrm{NaK}}$ towards potassium end-member compositions is more localized for diffusion in the direction perpendicular to (010) than perpendicular to (001). We suspect that the sharp rise in $D_{\mathrm{NaK}}$ towards potassium end-member compositions is due to the contribution of a $\mathrm{Na}^{+}$species occupying interstitial sites, which can contribute to the formation of vacancies on the alkali sublattice and by this enhance substitutional interdiffusion by the vacancy mechanism. In addition, interstitial $\mathrm{Na}^{+}$may constitute a fast diffusing Na-species by itself, where the latter mechanism may operate only within the $(010)$ plane and is unlikely to occur in the direction perpendicular to (010). In addition, the interplay between lattice distortion that is localized at the sharp diffusion fronts in the direction perpendicular to (010) and diffusion may cause a feedback leading to self-sharpening diffusion fronts.

\section{ACKNOWLEDGMENTS}

We thank Susan Schorr and Juergen Schreuer for providing gem quality sanidines from the Eifel and Andreas Wagner for preparing the single crystal plates with polished surfaces. We also thank D. Cherniak, R. Dohmen, and J. Hoefs for their reviews and comments on an earlier version of this paper. This work was funded by the Austrian Science Foundation, FWF grant I 474-N19 in the framework of the DFG-FWF research group FOR 741. 


\section{REFERENCES}

Abart, R., Petrishcheva, E., Wirth, R., and Rhede, D., 2009, Exsolution by spinodal decomposition II: Perthite formation during slow cooling of anatexites from Ngornghoro, Tanzania: American Journal of Science, v. 309 , n. 6 , p. $450-475$, http://dx.doi.org/10.2475/06.2009.02

Angel, R. J., Sochalski-Kolbus, L. M., and Tribaudino, M., 2012, Tilts and tetrahedra: The origin of the anisotropy of feldspars: American Mineralogist, v. 97, n. 5, p. 765-778, http://dx.doi.org/10.2138/ am.2012.4011

Bailey, A., 1971, Comparison of low-temperature with high-temperature diffusion of sodium in albite: Geochimica et Cosmochimica Acta, v. 35, n. 10, p. 1073-1081, http://dx.doi.org/10.1016/00167037(71)90023-8

Behrens, H., Johannes, W., and Schmalzried, H., 1990, On the Mechanisms of Cation Diffusion Processes in Ternary Feldspars: Physics and Chemistry of Minerals, v. 17, n. 1, p. 62-78, http://dx.doi.org/10.1007/ BF00209227

Benisek, A., Dachs, E., and Kroll, H., 2010, Excess heat capacity and entropy of mixing in ternary series of high-structural-state feldspars: European Journal of Mineralogy, v. 22, n. 3, p. 403-410, http:// dx.doi.org/10.1127/0935-1221/2010/0022-2028

Bertelmann, D., Förtsch, E., and Wondratschek, H., 1985, Zum Temperverhalten von Sanidinen: Die Ausnahmerolle der Eifelsanidin-Megakristalle: Neues Jahrbuch Mineralogische Abhandlungen, v. 152, p. 123-141.

Boltzmann, L., 1894, Zur Integration der Diffusionsgleichung bei variablen Diffusionskoeffizienten: Annalen der Physik, v. 53, p. 959-964, http://dx.doi.org/10.1002/andp.18942891315

Brady, J., 1995, Diffusion data for silicate minerals, glasses, and liquids, in Ahrens, T. J., editor, Mineral Physics and Crystallography; A Handbook of Physical Constants: Washington, D. C., American Geophysical Union, AGU Reference Shelf 2, p. 269-290.

Brady, J., and Yund, R., 1983, Interdiffusion of $\mathrm{K}$ and $\mathrm{Na}$ in alkali feldspars: homogenization experiments: American Mineralogist, v. 68, p. 106-111.

Britton, T. B., and Wilkinson, A. J., 2012, Stressfields and geometrically necessary dislocation density distributions near the head of a blocked slip band: Acta Materialia, v. 60, p. 5773-5782, http:// dx.doi.org/10.1016/j.actamat.2012.07.004

Cherniak, D., 2010, Cation diffusion in feldspars: Reviews in Mineralogy \& Geochemistry, v. 72, n, 1, p. 691-733, http://dx.doi.org/10.2138/rmg.2010.72.15

Christoffersen, R., Yund, R. A., and Tullis, J., 1983, Interdiffusion of $\mathrm{K}$ and $\mathrm{Na}$ in alkali feldspars: homogenization experiments: American Mineralogist, v. 68, n. 11-12, p. 1126-1133.

Crank, J., 1975, Mathematics of Diffusion, 2nd edition: New York, Oxford University Press, 424 p.

Demtröder, K., ms, 2011, Untersuchung zur Al/Si-Ordnung an Sanidin Megakristallen aus der Eifel: Bochum, Germany, Ruhr-Universität Bochum, Master's thesis.

Foland, K., 1974, Alkali diffusion in orthoclase, in Hofmann, A. W., Giletti, B. J., Yoder, H. S., and Yund, R. A., editors, Geochemical Transport and Kinetics: Washington, D. C., Carnegie Institution of Washington Publication 634, p. 77-98.

Freer, R., 1981, Diffusion in Silicate Minerals and Glasses: A Data Digest and Guide to the Literature: Contributions to Mineralogy and Petrology, v. 76, n. 4, p. 440-454, http://dx.doi.org/10.1007/ BF00371486

Giletti, B. J., and Shanahan, T. M., 1997, Alkali diffusion in plagioclase feldspar: Chemical Geology, v. 139, n. 1-4, p. 3-20, http://dx.doi.org/10.1016/S0009-2541(97)00026-0

Giletti, B., Semet, M., and Kasper, R., 1974, Self-diffusion of potassium in low albite using an ion microprobe: Geological Society of America Abstracts with Programs, 6, p. 754.

Hokason, S. A., and Yund, R. A., 1986, Comparison of alkali interdiffusion rates for cryptoperthites: American Mineralogist, v. 71, n. 11-12, p. 1409-1414.

Jones, A., Islam, M., Mortimer, M., and Palmer, D., 2004, Alkali ion migration in albite and K-feldspar: Physics and Chemistry of Minerals, v. 31, n. 5, p. 313-320, http://dx.doi.org/10.1007/s00269-0040389-8

Kasper, R., ms, 1975, Cation and Oxygen diffusion in albite: Providence, Rhode Island, Brown University, Ph. D. Dissertation, 298 p.

Kroll, H., Schmiemann, I., and von Coelln, G., 1986, Feldspar solid solutions: American Mineralogist, v. 71, p. 1-16.

Lin, T. H., and Yund, R. A., 1972, Potassium and Sodium Self-Diffusion in Alkali Feldspar: Contributions to Mineralogy and Petrology, v. 34, n. 3, p. 177-184, http://dx.doi.org/10.1007/BF00373289

Manning, J. R., 1968, Diffusion Kinetics for Atoms in Crystals: Princeton, New Jersey, Van Nostrand, 257 p.

Matano, C., 1933, On the Relation between the Diffusion-Coefficients and Concentrations of Solid Metals (The Nickel-Copper System): Japanese Journal of Physics, v. 8, p. 109-113.

Maury, R., 1968, Conductibilité électrique des tectosilicates I. Méthode et résultats expérimentaux: Bulletin de la Société Francaise de Minéralogie et de Cristallographie, v. 91, n. 3, p. 267-278.

Mehrer, H., 2007, Diffusion in Solids - Fundamentals, Methods, Materials, Diffusion-Controlled Processes: Heidelberg, Springer, Springer Series in Solid State Science, v. 155, 672 p.

Neusser, G., Abart, R., Fischer, F., Harlov, D., and Norberg, N., 2012, Experimental Na/K exchange between alkali feldspar and $\mathrm{NaCl}-\mathrm{KCl}$ salt melt: chemically induced fracturing and and element partitioning: Contributions to Mineralogy and Petrology, v. 164, n. 2, p. 341-358, http://dx.doi.org/10.1007/s00410012-0741-9

Parsons, I., and Lee, M. R., 2005, Minerals are not just chemical compounds: The Canadian Mineralogist, v. 43, n. 6, p. 1959-1992, http://dx.doi.org/10.2113/gscanmin.43.6.1959

Petrishcheva, E., and Abart, R., 2009, Exsolution by spinodal decomposition I: evolution equation for binary 
mineral solutions with anisotropic interface energy: American Journal of Science, v. 309, n. 6, p. 431-449, http://dx.doi.org/10.2475/06.2009.01

Petrishcheva, E., Abart, R., Schäffer, A. K., Habler, G., and Rhede, D., 2014, Sodium-potassium interdiffusion in potassium-rich alkali feldspar I: Full diffusivity tensor at $850^{\circ} \mathrm{C}$ : American Journal of Science, v. 314, n. 9, p. 1284-1299, http://dx.doi.org/10.2475/09.2014.02

Petrović, R., ms, 1972, Alkali Ion Diffusion in Alkali Feldspars: New Haven, Connecticut, Yale University, Ph. D. Thesis, $262 \mathrm{p}$.

1973, The Effect of Coherency Stress on the Mechanism of the Reaction Albite $+\mathrm{K}^{+} \rightleftharpoons$ K-Feldspar + $\mathrm{Na}^{+}$and on the Mechanical State of the Resulting Feldspar: Contributions to Mineralogy and Petrology, v. 41, n. 2, p. 151-170, http://dx.doi.org/10.1007/BF00375040

Riley, T. R., and Bailey, D. K., 2003, Barium-rich sanidine megacrysts from the West Eifel (Germany): Neues Jahrbuch für Mineralogie - Monatshefte, v. 41, p. 18-30, http://dx.doi.org/10.1127/0028-3649/2003/ 2003-0018

Schäffer, A. K., Jäpel, T., Zaefferer, S., Abart, R., and Rhede D., 2014, Lattice strain across Na-K interdiffusion fronts in alkali feldspar: an electron back-scatter diffraction study: Physics and Chemistry of Minerals, http://dx.doi.org/10.1007/s00269-014-0692-y

Scheidl, K., Schäffer, A. K., Petrishcheva, E., Habler, G., Fischer, F., Schreuer, J., and Abart, R., 2014, Chemically induced fracturing in alkali feldspar: Physics and Chemistry of Minerals, v. 41, n. 1, p. 1-16, http://dx.doi.org/10.1007/s00269-013-0617-1

Sippel, R. F., 1963, Sodium self diffusion in natural minerals: Geochimica et Cosmochimica Acta, v. 27, n. 1, p. 107-120, http://dx.doi.org/10.1016/0016-7037(63)90073-5

Spear, F. S., 1993, Metamorphic Phase Equilibria and Pressure-Temperature-Time Paths: Washington, D. C., Mineralogical Society of America Monograph, 799 p.

Weitz, G., 1972, Die Struktur des Sanidins bei verschiedenen Ordnungsgraden: Zeitschrift für Kristallographie, v. 136, n. 5-6, p. 418-426, http://dx.doi.org/10.1524/zkri.1972.136.5-6.418

Yund, R., 1983, Diffusion in Feldspars, in Ribbe, P. H., editor, Feldspar Mineralogy: Mineralogical Society of America, Reviews in Mineralogy, v. 2, p. 203-222. 